\title{
The implications of rural perceptions of water scarcity on differential adaptation behaviour in Rajasthan, India
}

\author{
Chandni Singh ${ }^{1,2}$ (1) $\cdot$ Henny Osbahr ${ }^{1} \cdot$ Peter Dorward $^{1}$
}

Received: 15 June 2017 / Accepted: 8 May 2018 / Published online: 29 May 2018

(C) The Author(s) 2018

\begin{abstract}
Water scarcity is one of the most critical issues facing agriculture today. To understand how people manage the risk of water scarcity and growing pressures of increased climate variability, exploring perceptions of risk and how these perceptions feed into response behaviour and willingness to adapt is critical. This paper revisits existing frameworks that conceptualise perceptions of environmental risk and decision-making, and uses empirical evidence from an in-depth study conducted in Rajasthan, India, to emphasise how individual and collective memories, and experience of past extreme events shape current definitions and future expectations of climatic risks. In doing so, we demonstrate the value of recognising the role of local perceptions of water scarcity (and how they vary between and within households) in constructing social vulnerability. This expanded understanding of risk perception is critical for incentivising individual adaptation and strengthening local adaptation pathways.
\end{abstract}

Keywords Perceptions $\cdot$ Water scarcity $\cdot$ Adaptation $\cdot$ Social vulnerability $\cdot$ Memory $\cdot$ Climate change $\cdot$ India

\section{Introduction}

Managing water scarcity has emerged as a growing challenge globally, particularly for rural livelihoods dependent on rainfed agriculture (United Nations 2015; Gosling and Arnell 2016; Mekonnen and Hoekstra 2016). In the face of increasing demand from urbanisation, cultivation of new

Editor:Chinwe Ifejika Speranza

Electronic supplementary material The online version of this article (https://doi.org/10.1007/s10113-018-1358-y) contains supplementary material, which is available to authorized users.

Chandni Singh

csingh@iihs.ac.in

Henny Osbahr

h.osbahr@ reading.ac.uk

Peter Dorward

p.t.dorward@ reading.ac.uk

1 School of Agriculture, Policy and Development, University of Reading, Whiteknights, P.O. Box 237, Reading, Berkshire RG6 6AR, UK

2 Indian Institute for Human Settlements, Bangalore City Campus, No. 197/36, 2nd Main Road Sadashivanagar, Bangalore, Karnataka 560 080, India water-demanding crops, agricultural intensification, misuse and over extraction, population pressures, and the impacts of climate variability and change, water scarcity remains a crucial limiting factor driving farmer vulnerability. The Indian state of Rajasthan is an illustrative example of these interrelated challenges. Rajasthan has the country's largest arid and semi-arid area and faces acute water scarcity due to erratic monsoonal rainfall as well as critically overexploited groundwater resources.

While science provides the tools to understand and manage water resources, it is also vital to understand how rural people perceive local water scarcity and how this is socially differentiated. A failure to appreciate how people perceive the magnitude of environmental and climatic risks or their implications for livelihoods has been identified as significant barriers to adaptation (Patt and Schröter 2008; Singh et al. 2016). Perceptions shape the responses people undertake (Nguyen et al. 2016; Sutcliffe et al. 2016) to cope, adapt, not adapt or maladapt. In recent years, there have been an increasing number of studies capturing farmer perceptions of risk. Studies have explored perceptions of climate variability and climate change (Banerjee 2014; Nguyen et al. 2016; Sutcliffe et al. 2016) and compared these to meteorological data (Burnham et al. 2016; Meze-Hausken 2004; Mubaya et al. 2012; Simelton et al. 2013; Sutcliffe et al. 2016), but they do not always fully interrogate the underlying factors that shape these views. 
There has been a geographic concentration of research on the African continent, with far fewer studies in Asia examining causes and implications of differential perceptions (notable exceptions include Vedwan 2006; Becken et al. 2013; Banerjee 2014; Dhanya and Ramachandran 2016). The implications of this gap in examining differential perceptions are critical to address since insights into risk perception can help identify entry points into incentivising adaptive behaviour. More recently, researchers have focussed on the implications of perceptions on adaptive action (Eakin et al. 2016; Grothmann et al. 2013) and demonstrated how socio-cultural factors, and policy and institutional environments mediate the translation of risk perceptions into response behaviour (Burnham et al. 2016; Eakin et al. 2016; Nguyen et al. 2016). We argue that revisiting frameworks that seek to understand how and why perceptions of water risk differ and translate into differential behaviour is important to manage or respond to future risk. It is important to capture farmers' perceptions of water scarcity because it helps explain investment decisions, contributes to scientifically justified adaptive behaviour (Gbetibouo 2009; Maddison 2007; Slegers 2008b), and can motivate better design of projects aimed at natural resource management and livelihood adaptation. Such inquiry has direct implications for improving our approach to climate change adaptation, which is, at its core, a behavioural change.

We use a modified version of Slegers' (2008) framework of risk perception (detailed in the next section) to highlight how experience, memory, definition, and expectations interact to form people's notions of risk and response. We build upon this framework because it highlights the role of often-ignored, intangible socio-cognitive factors such as memory and expectations in risk formulation. This paper seeks to demonstrate the value of recognising the role of local perceptions of water scarcity because these perceptions construct local social vulnerability and shape opportunities for effective adaptation behaviour. We explore the factors that shape perceptions of risk and explain these socially differentiated views of water scarcity. The paper draws on empirical data from India to emphasise how both individual and collective memories and experience of past extreme events shape current definitions and future expectations of climatic risks. These insights allow reflection on existing conceptual approaches about perceptions and implications for understanding adaptive action to water scarcity.

\section{Conceptualising perceptions of risk}

Rural livelihoods are vulnerable to multiple climatic and nonclimatic risks. People in rural areas prepare for, and respond to, these risks through multiple strategies, such as storing food, changing agricultural practices, diversifying livelihoods, leveraging social networks, or migrating. Behavioural changes, such as those involved in adaptation, require people to make decisions from multiple choices. Risk perception is fundamental to this process of risk management and behavioural change, and people tend to respond to risks they perceive (Gbetibouo 2009; Maddison 2007; Murray-Prior 1998). While the final decision is driven by multiple factors like asset availability, time requirements, familiarity, and broader narratives of climatic change (Mertz et al. 2009), perceptions of risk have been identified as central in driving human behaviour (Bowditch et al. 2001; Fishbein and Ajzen 2011; Gbetibouo 2009; Grothmann and Patt 2005).

Studying farmers' perceptions of drought in semi-arid central Tanzania, Slegers (2008b:2108) define perceptions as 'a range of judgments, beliefs and attitudes from which it can be inferred that perception is neither universal nor static, but rather a valueladen, dynamic concept'. These perceptions of risk conform to personal value judgements (Ferrier and Haque 2003) and sociocultural norms (Martínez-García et al. 2013; Nguyen et al. 2016), and are shaped by experience and memory of past events (Mertz et al. 2009; Meze-Hausken 2004), definitions of risks and acceptable thresholds (Grothmann and Patt 2005; Slegers 2008a), and expectations of such events to occur in the future (Meze-Hausken, 2004). These definitions and expectations are further based on what is assumed 'normal', through short-term experiences during the prior five seasons (Coe and Stern 2011) and long-held beliefs and cultural norms, such as traditional calendars (Burnham et al. 2016; Vedwan and Rhoades 2001). Traditional practice, environmental beliefs or water use within agriculture can be explained through place attachment, the cognitive-emotional bond that forms between individuals and locations that become meaningful to them (Scannell and Gifford 2017), such as for communities living in one place over several generations.

Several frameworks attempt to conceptualise risk perception and its role on behaviour. Drawing on examples of flooding in urban Germany and drought in rural Zimbabwe, Grothmann and Patt (2005) found that risk perception and perceived adaptive capacity shape adaptive action. Their Model of Private Proactive Adaptation to Climate Change (MPPACC) builds upon the premise that people do not necessarily have objective ability to act as modelling approaches tend to assume, and their adaptation behaviour is mediated by socio-cognitive factors. Feola et al. (2015) also conclude that adaptation is inherently a social process and thus decisionmaking models must factor in socio-cultural contexts and acknowledge how institutional networks interface with biophysical factors such as soil type or farm location. They highlight that farmers respond to multiple cross-scale pressures, such as market price volatility, and that decisions are mostly taken in response to short-term immediate risks rather than to meet longer-term goals. Studying farmer perceptions of climate change in the Loess Plateau region of China, Burnham et al. (2015:22) find that perceptions are 'entangled'- shaped concurrently by socio-cultural practices and biophysical factors so 
that these 'hybrid' understandings of the climate shape daily practices and responses.

Other frameworks highlight how adaptive behaviour is driven by socio-cultural context (Adger et al. 2013; Arunrat et al. 2017; Feng et al. 2017; Feola et al. 2015; Nguyen et al. 2016), actors external to the decision makers themselves (Feola et al. 2015), the institutional environment (Eriksen et al. 2015; Nguyen et al. 2016), individual cognitive influences (Grothmann et al. 2013; Eakin et al. 2015; Singh et al. 2016), and notions of identity and place (Marshall et al. 2012; Singh 2014). Social memory also plays a role in community resilience through individuals (personal life histories) and stakeholder groups (collective memory) (Olick and Robbins 1998). Adger et al. (2005) and Folke (2006) emphasise that social memory comes from the diversity of individuals and institutions that draw on reservoirs of practices, knowledge, values and worldviews, and that it is crucial for preparing a system for building resilience and for coping with surprises. The ways that experiences are held in social memory are shaped by, and in turn shape, institutionalised forms of learning, communication, knowledge transfer and institutional thickness. Experiences are also shaped by the fact that personal choices can be selfreinforcing and, therefore, often self-fulfilling. These factors collectively help to explain the pathways that communities take when responding to water scarcity. Pathways can be anticipatory and non-deterministic, but social memory of past experience remains a crucial element that leads to learning and adjustment (Wilson 2015). Furthermore, not all people intending to change behaviour are able to do; for example, the cost of action or a need to conform to social norms may restrict certain adaptation behaviour (Curry et al. 2015).

Taylor et al. (1988) captured these aspects in a framework of perception, further developed by Slegers (2008b), which focusses on memory, experience, definition, and expectation as key factors that construct meaning and shape perceptions (Fig. 1). We draw on this framework to organise farmer perceptions of water scarcity and climate variability and understand how they are socially differentiated. This framework goes beyond previous frameworks by capturing socio-cognitive aspects of risk perception and highlighting normative perceptions of environmental risk, both of which are understudied (Arunrat et al. 2017; Elrick-Barr et al. 2016; McDonald et al. 2015). The framework also underscores how risk perceptions draw on (1) the wider institutional regime and biophysical environment, and (2) an individual's memories, experiences, expectations and definitions of risk, to shape adaptive behaviour. This mapping allows us to understand the implications of risk perceptions on adaptive behaviour, the key focus of this paper.

The framework has four key components: experience, memory, definition, and expectations. Previous experiences of, and interactions with the environment (direct or indirect) provide a reference against which people compare expectations of future

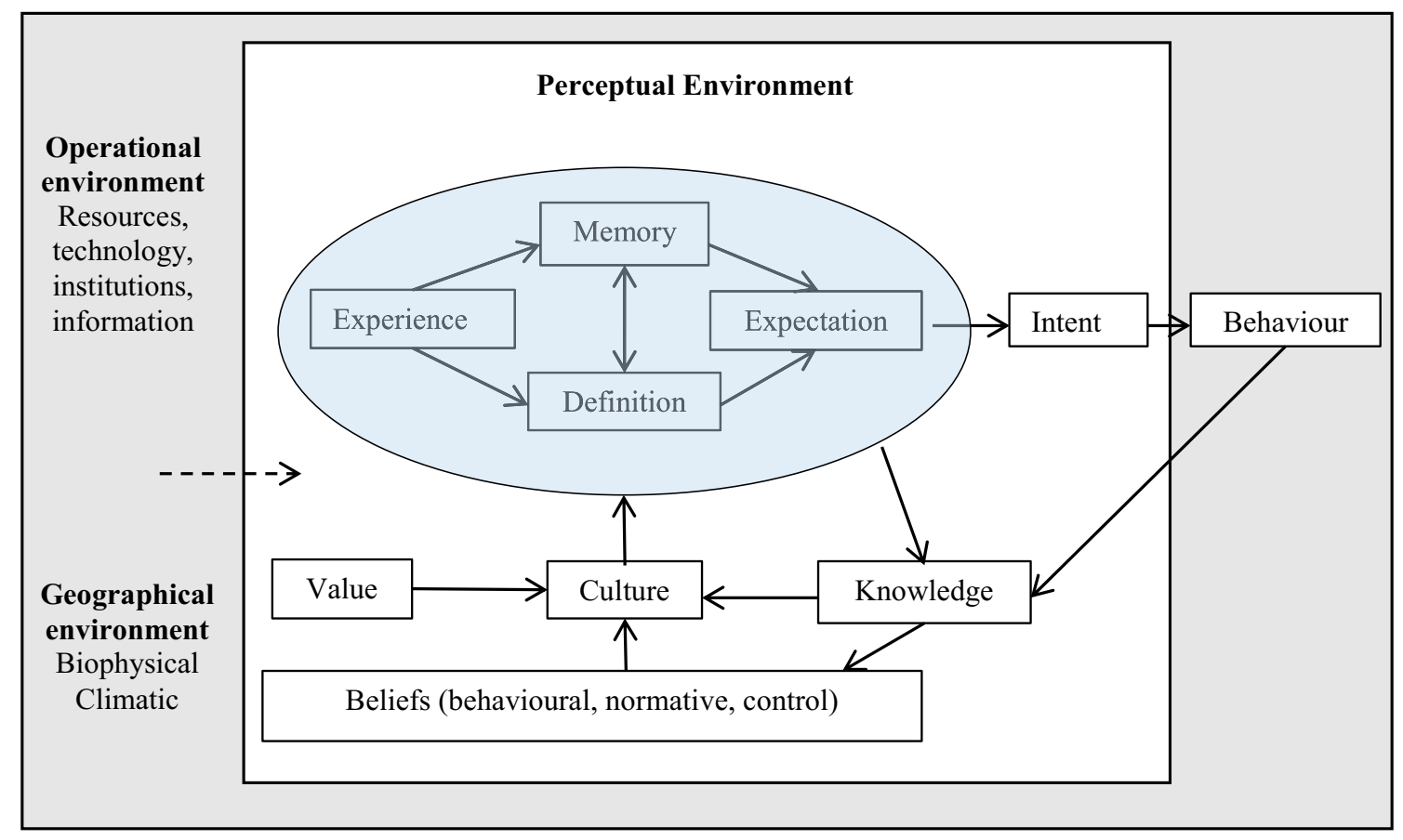

Fig. 1 Framework to understand human perceptions of the environment. The circle shaded blue (containing memory, expectation, experience, and definition) covers scope of this paper. Source: Adapted from Taylor, 1988; Slegers 2008b. Note: The operational environment and geographical environment shape the perceptual environment which in turn is an outcome of experience, memory, definition (of the environment and changes in it) and expectations of future change. The perceptual environment is also mediated by community-held values and beliefs as well as the cultural context. The operational and geographical environments go through the perceptual environment to shape intent (to act) and finally a behavioural outcome (which can be no action, coping, adaptation) 
environment. These experiences affect people's memory of an event and how they define future occurrences. Definition alludes to the criteria people evolve to describe a particular environmental phenomenon (Taylor et al. 1988). For example, people may use number of days without rain, extent of crop damage, or severity of food shortages to describe drought. Memory is inherently subjective because what is remembered and forgotten differs between people (Ferrier and Haque 2003). Crucially, memory is not only a collection of impressions of past events but also the ability to recall them (Hulme et al. 2009). Studies examining people's memory of climate variability and rainfall patterns show that the details and accuracy of memory change based on personal constructs (Mertz et al. 2009; Osbahr et al. 2011). Thus, people may exaggerate certain drought events and forget others based on how they were affected (Slegers 2008a) or display a tendency to recall recent events more frequently and with greater clarity that older periods (Ferrier and Haque 2003; Marx et al. 2007).

The two-way arrow between memory and definition implies that one remembers an event based on how one defines it but also defines it on based on one's memories of it. Criteria used to define environmental phenomena also depend on experiences of similar events. For example, recurring exposure to a drought makes people perceive water scarcity as 'normal' (Marx et al. 2007) as opposed to areas that receive relatively more rainfall. All these elements (experience, memory, and definition) shape expectations of how the environment will be in the future (Murray-Prior 1998), and ultimately affect behaviour. Here, behaviour is understood as an outcome or action with an inherent decision-making stage where choice is exercised amongst several alternatives. In the context of water scarcity and climate variability, behavioural outcomes can range from no response to coping to adapting (Singh et al. 2016). While Singh et al. (2016) have already elaborated the links between behaviour and value, culture, knowledge and beliefs for this study location, they highlight the need to improve insight between these factors and the implications of risk perceptions from other aspects within the perceptual environment (Fig. 1).

This is important because being mutable and value-laden, perceptions may attribute phenomena to wrong causal factors (Osbahr et al. 2011). However, 'wrong' perceptions do not imply good or bad judgement but highlight that perceptions may not necessarily reflect actual data and result in misattributions (Simelton et al. 2013; Sutcliffe et al. 2016). In fact, in the 'perception approach', White (1966) questions the superiority of the 'expert viewpoint' and stresses that each opinion has its own validity, with no one 'right' response to a hazard. Furthermore, while individual risk perception is a cognitive process based upon emotion rather than reason, objective risk assessment is based upon observed scientific data, and is thus not tempered by individual belief systems or circumstances (Ferrier and Haque 2003). This can result in mismatches between perceived and observed risk.
The insights from these frameworks and understandings of differential perceptions can be used to assess local adaptation to water scarcity in dryland India. The paper focusses on contributing to the identified gap in understanding of risk perception, to consider the role of experience and social memory, definition and expectation in shaping differential social vulnerability and behaviour. These dimensions are usefully organised in Slegers' (2008) framework to highlight the importance of socio-cognitive drivers of adaptation behaviour.

\section{Methodology}

\section{Site selection and sampling}

Rajasthan is a drought-prone state in India supporting 5.5\% of India's population, $10 \%$ of its livestock but only $1.15 \%$ of the country's water resources (Government of Rajasthan 2014). One third of its land is classified as semi-arid, and low rainfall, increasing population, and groundwater exploitation have led to acute water scarcity (Goel et al. 2006). Rajasthan is expected to face an increase in erratic precipitation (Singh et al. 2010), increasing average temperature and evapotranspiration (Mall et al. 2006), accelerated desertification, and land degradation (Ajai Arya et al. 2009), all leading to the state slipping into absolute water scarcity in the future (Government of Rajasthan 2014).

Water scarcity in Rajasthan has received sustained financial, policy, implementation, and research attention, with more emphasis on the north-western arid tracts than the relatively water-rich south-eastern regions. This emphasis has overlooked the fact that even areas with high average rainfall often face acute water scarcity (Government of Rajasthan 2014; Rathore 2005) and that southern Rajasthan is geographically, culturally and economically unique within the rest of the region. There exists a significant gap in bridging scientific and social approaches to understand why this region has steadily remained low on all development indices (pers. comm. State Government Official, June 2012).

The relative paucity of work in southern Rajasthan, with the added complexity of being a tribal district, led us to choose Pratapgarh as the study area. Annual average rainfall in Pratapgarh is $875 \mathrm{~mm}$ (Pratapgarh NIC 2012) but an underrock of unfractured basalt rock discourages percolation. Poor storage infrastructure and inadequate local institutions for conservation compound water scarcity (Foundation for Ecological Security, 2006; Government of Rajasthan 2014). Pratapgarh is predominantly tribal, with $72 \%$ of the population made up of Meena tribals whose main source of livelihood is a combination of agriculture, wage labour, and selling forest products (Foundation for Ecological Security 2006). Common land for grazing and forests make up 32\% of the landscape with villages scattered in between (Pratapgarh 
NIC 2012). However, unfavourable tenure arrangements, poor management systems, overgrazing, illegal deforestation, and inadequate groundwater recharge have led to land degradation (De, 2005). Sixty-five per cent of the population falls below the poverty line, and the average literacy rate is $47 \%$ (Pratapgarh NIC 2012). Most families are debt-ridden and face food grain scarcity for 3-6 months per year (Foundation for Ecological Security 2006). Exposure to erratic rainfall, inappropriate and often exploitative natural resource utilisation, poor representation in local governance institutions, and breakdown of traditional social arrangements have made local livelihoods more sensitive to climatic and non-climatic risks.

\section{Data collection and analysis}

Understanding and effectively capturing peoples' perceptions is difficult (Simelton et al. 2013) since it involves capturing often intangible views, disentangling perceived cause and effect, and adopting the role of an unbiased yet discerning listener. We use a constructivist approach, which follows that reality is constructed in multiple ways based on social context, location and actions, and perceptions of social actors.

Data were collected over 10 months of fieldwork (October 2011-July 2012) through focus group discussions (FGD), semi-structured questionnaires, in-depth case studies, key informant interviews (KII), observations, and document reviews (Table 1). The researchers 'entered' the site through a local NGO, the Foundation for Ecological Security (from here on FES), working in Pratapgarh for the past 6 years. ${ }^{1}$ NGOs can serve as local area experts, facilitate community acceptance of the researcher and help access key informants. We were aware that using an NGO could lead to potential selection bias and minimised this by immersion in the research site through a year-long on-site fieldwork, following ethical protocols laid out by the home university, and triangulating findings through multiple methods.

Within Pratapgarh, two village clusters were chosen based on their representativeness of the socio-ecological characteristics of the district and willingness of respondents to participate in the research. Further details of the sampling strategy and representativeness of the surveyed households are outlined in Singh et al. (2016). In the first phase of data collection, all households within each cluster $(n=219)$ were surveyed to adequately represent farming families from different socio-economic groups. Key informants such as village leaders, members of community-based organisations, agriculture extension workers, and NGO officials were also

\footnotetext{
${ }^{1}$ Foundation for Ecological Security (FES) has been working in dryland areas in 6 states of India since 2001 focussing on watershed development, ecological restoration, common land regeneration and livelihood enhancement with a strong element of local institutional building and strengthening local governance. [More details at http://www.fes.org.in].
}

interviewed. In the second phase of fieldwork, 14 households were purposively chosen from each location as case studies ${ }^{2}$ to capture a variety of response strategies and follow decisionmaking pathways about why certain households choose to adapt or not.

Semi-structured questionnaires were used to collect demographic data and livelihood information followed by openended questions on perceptions of water scarcity, vulnerability to it, and drivers of and responses to scarcity. The term 'climate change' was not explicitly mentioned because such terminology may not be formed in local semantics and people often used different terminology to explain observed weather and water changes. The questioning was conversational and probed how external information (e.g. through extension workers, NGO staff) shaped the way people validated their knowledge. The questionnaire contained open-ended questions on drivers and constraints to adaptive capacity, actors and processes of decision-making between adaptive strategies, and efficacy of interventions by various actors towards building adaptive capacity.

Within a household, questionnaires were administered to the household head. If the household head was absent, the spouse or next of kin was interviewed. Wherever possible, it was preferred to have more than one respondent from a household, especially ensuring representation from both genders. Since women would often not speak in front their fathers-inlaw or nod in agreement with their husbands, as common in rural North India, in such situations women were spoken to outside their homes (for example, by following them into kitchen gardens to pick up on earlier cues).

Quantitative data were analysed in MS Excel and qualitative data in NVivo (QSR 2012). Data were coded using relevant themes in an iterative manner following an inductive approach and then analysed along socio-economic and demographic variables. The data was coded by one researcher thus ensuring stability (similar use of a code across the dataset) and accuracy. Narratives from case studies were also analysed to uncover intra-household dynamics around risk perception and decision-making.

\section{Results}

We first discuss the major perceptions people hold, using Taylors and Slegers' framework (Fig. 1), followed by how perceptions are differentiated. While we focus on dimensions of memory, experience, definitions and

\footnotetext{
${ }^{2}$ The 14 households were chosen based on different economic strata (stateidentified categories of above poverty line, below poverty line and poorest of the poor), social group (Meena, Rajput), access to natural resources and physical assets (landholding, well ownership, livestock ownership, access to forests, communal water sources), and livelihood types (farmers, traders, labourers, migrants).
} 
Table 1 Details of data collection carried out in both locations

\begin{tabular}{lll}
\hline & Location 1 & Location 2 \\
\hline Fieldwork & Nov 2011-Jan 2012 & March 2012-May 2012 \\
No. of hamlets/villages & 6 hamlets & 2 villages \\
No. of households interviewed & 133 & 86 \\
Focus groups (4-5 participants/group) & 3 & 2 \\
In-depth case studies & 8 & 6 \\
Key informants & 7 & 5 \\
Location characteristics & & \\
Total households & 153 & 92 \\
Average landholding size & 1.16 acres & 1.26 acres \\
Soil type & Black soil, plateaus have rocky surface and less soil fertility (brown soil); valleys have stony red soil \\
Caste & Meena (tribals) & Meena (40\%), Rajput (60\%) \\
Public amenities in Panchayat ${ }^{\mathrm{a}}$ & 4 primary schools, 1 high school, & 1 primary school, 1 primary health \\
& 1 crèche, 2 primary health centres & centre, 1 crèche (all $>8$ km away) \\
Accessibility and road networks & Hamlets are 1-9 km away from & Hamlets are 5-12 km away from \\
& metaled road head & metaled road head
\end{tabular}

${ }^{\text {a }}$ Locally elected, village-level governing body, which is part of a three-tier local governance system

expectations, we explain these perceptions through a wider understanding of the perceptual environmental (local values, culture, knowledge and beliefs) with recognition also of operational and geographical environmental influences.

\section{Memory and experience shape perceptions of water scarcity}

When it comes to memory, the immediate often takes precedence over the past (Hertwig et al. 2004) because constraints in human cognition give weightage to more 'impressionable' events (Ferrier and Haque 2003) and the consequences of those events are perceived closer than those in the distant past. Respondents exhibited a bias for recent events: farmers exaggerated rare, high-impact events and downplayed more commonly occurring, low-impact 'background' events (Table 2).

Memories were also closely tied to important personal or political events. In one hamlet, a respondent spoke of a long period of water scarcity around the time she had her first child. The memory of childbirth (a significant personal event) signposted her memories of having to carry pots of drinking water for household consumption, making the experience of a water-scarce period easy to retrieve. Marx et al. (2007:54) explain this by the 'availability heuristic', defined as 'a rule of thumb that allows people to solve problems based on what they remember and how easily their memory is retrieved'. This ease of retrievability is closely linked to significant landmarks in a person's life. During the interviews, farmers identified periods of scarcity as times when the Food for Work programme for famine relief was underway. Many respondents' memories were tied with relief work with the common understanding of 'if there was relief work, there must have been a drought'.

Memory was also 'borrowed' from elder relatives and neighbours. For example, when discussing past drought or famine events, most respondents, irrespective of their age, mentioned 'chhappan ka kaal' (the 'Famine of 1956') referring to the great famine of 1899-1900, named after dates in the Vikram Era calendar (Rajesh 2000). Thus, memory can be constructed individually or collectively. This relies on the tradition of oral storytelling where elders in a community narrate their memories and experiences of past extreme events or periods of scarcity. Descriptions included lengthy narrations - from standing in long queues to receive government rations, to people eating 'kodra' gruel (Paspalum scrobiculatum, a coarse millet) and tree bark. Youngsters often joined in enthusiastic and descriptive narrations of the event that they had obviously not experienced personally but had heard of from their grandparents. The youngsters revelled in recounting the memory because they were young enough to be removed from the discomfort of experiencing the drought but old enough to appreciate that it was an important historic event.

Farmers also used important festivals and major events in traditional calendars as landmarks to navigate their way and anchor their impressions of the past. Culturally important periods of fasting and prayers were used as signposts to gauge whether rainfall or temperature were 'normal' or not.

Narratives of experience were sharper when the climatic event had a direct impact on household livelihood through decrease in or complete loss of crops (Table 2). Surprisingly, 
Table 2 Indirect indicators of water scarcity and drought: definitions, memories, experiences and expectations

Indirect indicators of water scarcity

Decreased crop production

Inability to water crops

Soil moisture

Leaving land fallow

Shift in sowing times

Food insecurity

Memories

Comparisons with similar past experiences or current occurrences

Bias for the recent

Memories as linked to impact on livelihoods

Heightened memories of the past

Signposted by festivals

Experiences

Impact on crop production

Food insufficiency, dependence on government food rations, public works

Expectations

Hopes for the future
'Excessive rains in 2011 caused 50\% damage to our kharif crop. We only got 1.5 sacks of soybean/bigha instead of four. In winter, we grew mustard but it dried up because there wasn't enough soil moisture.'

'If we were water secure, we could grow vegetables and sell them in the market. We don't even have enough water for wheat. I can only irrigate it once and that will reflect in the production but there is no option.'

'If there is more rain, the soil remains wet, and we can use tractors. Otherwise, we have to use bullocks for all agricultural work.'

'I have only grown some wheat and left rest of my land fallow because of insufficient water.'

'Wheat sowing has shifted a bit early because our wells dry earlier. To get maximum benefit from soil moisture, as soon as the rains get over and soybean is harvested, we sow wheat.'

'When less water falls, especially for 2-3 years in a row, we cannot grow wheat and have no food. Some years we have even survived solely on government rations.'

'15-20 years ago, it used to rain a lot. Then no maize would ripen and crops would rot. Slowly rainfall decreased and in 2008-2010, we faced a lot of scarcity. Now in 2011, rain has increased again, like old times.'

'This year we had very heavy rain and our entire crop rotted. Yes, other years also have rain but I can't remember much about them now.'

'There hasn't been a totally dry year but once ( 15 years ago) we had a period of water scarcity. We relied on labour at that time. Some people went to the towns and did work there.'

'When I was small it used to rain for six months but we had no means of capturing and storing it. Now it only rains for $2-2.5$ months. We have motors and wells to capture and utilise water but no rain!'

'Thirty years ago it used to rain till Navratri (October) and often till Diwali (October/November). Now rains stay only till Shraad (September). Winter rains have completely stopped now and it rains for just a few days, if at all.'

'Sometimes, in spite of our best efforts, we get poor yields because rainfall is less, like it was in 2000. Then we rely on labour and the winter crop for food.'

'In drought years, the government increases public works like digging ponds. This helps provide income when crops fail.'

'I think it will not rain as heavily next year as it did this year (2011). We lost half our soybean crop in the rains this year and suffered big losses.' people reported that they have not experienced actual drought although they were unanimous in their experience of the occurrence of dry spells every year. This contrasted sharply with past meteorological data which categorises Pratapgarh a 'frequently drought-prone area', with a probability of drought occurring every 5 years (Government of Rajasthan, 2005). Respondents defined 'actual drought' as complete failure of rains and total loss of crops as opposed to 'regular water scarcity' which was partial crop loss due to monsoonal dry spells and limited water availability in winter. To illustrate: 'In my opinion, there has been no drought here. There has been Famine Relief Work but that is not because of drought. That was because crops dried up because of less rain.' HH_117_J. Dry spells were accepted as a 'normal' feature to be tolerated and overcome annually. This tolerance for water scarcity made farmers under-report dry spells because of the regularity and commonness of their experiences.
As Bokil (2000:4171) notes, 'drought in arid and semi-arid regions is not a calamity, like an earthquake or a cyclone, but a regular climatic feature' and goes on to observe that irrespective of meteorological drought as defined by the Government of India, Rajasthan faces permanent agricultural drought (insufficiency of water to meet crop demands).

\section{Definitions and expectations of water scarcity}

To understand drought reporting in Pratapgarh, understanding the language of water scarcity is important. The Hindi word for drought is 'sukha', which implies complete dryness. According to farmers, this had not occurred in the past 30 years. However, non-farmer key informants drew a different picture: local government and NGO officials confirmed low to moderate drought every 4-5 years (pers. comm., May 
2012). Further discussions revealed that locally, drought is defined by extreme hunger, with the word ' $k a a l$ ' denoting famine, being used synonymously with 'akaal' or drought. Thus, food security had a crucial role in defining drought and definitions of an extreme event (drought) affected the experience and hence reporting of it.

Of the total respondents $(n=219), 73 \%$ ranked water scarcity as the most important factor limiting their agriculture, and identified secondary constraints to be unavailability of agricultural inputs (seed, fertiliser, and pesticide), and lack of irrigation infrastructure and farm implements. People used direct and indirect indicators to define water scarcity and risk from climate variability (Fig. 2). Direct indicators were typically understood as tangible, visible indicators ${ }^{3}$ while indirect indicators were factors that suggested water scarcity as perceived by second-order impacts. In both locations, the most common direct indicator of water scarcity was reduction in rainfall amount, followed by less water in wells in location 1 (49\%) and less water in common water bodies in location $2(33 \%)$. This difference between locations was because of relatively lower well density and thus higher dependence on streams and ponds for irrigation in location 2 .

Farmers reported that rainfall amount alone was a poor indicator and well-spaced rainfall (moderate rain over four monsoon months) that percolates into the soil was more crucial for ensuring a good crop. Also, though we segregate indicators for clarity, in reality, they were interlinked and coproduced an understanding of water scarcity. For example, decreased water in wells was perceived by lowered water availability to irrigate fields during dry spells, lowered drinking water availability, and increased reliance on governmentsponsored tankers for drinking water in summer.

Some farmers (10 and $16 \%$ in locations 1 and 2, respectively) used soil moisture to indicate water scarcity. These perceptions were closely tied to soil type in the respondent's field. Distinctions were made based on soil colour, fertility, and water holding capacity. Overall, darker, black soils were considered more fertile and retained more moisture as compared to lighter, sandy soils, which had more gravel. Soil moisture (and thus water availability) was also perceived through the need for tractors or bullocks for ploughing (Table 2).

Importantly, most indicators of climate variability were from seasons that are economically crucial to the farming system. For example, most perceptions of change were from the monsoon season (main growing season) and fewer changes were perceived after April (after crop harvest) and in summer (lean period, when land is left fallow).

The most common indirect indicators revolved around crop production, food insecurity, and increasing dry spells (Table 2). Though indirect, these factors are rendered tangible

\footnotetext{
$\overline{3}$ Throughout the paper, we use the word 'indicator' to discuss the factors/ words/proxies farmers used to define water scarcity and climate variability.
}

through second-order impacts on household income and food security. Use of indicators like household food insecurity and inability to pay loans was relatively higher in location 2 where fewer non-agricultural sources of income meant that decreases in crop production affected household income directly. These differences between locations highlight how factors such as relative isolation (location 2 is further from the Panchayat headquarters, market, and has limited road access), lower soil quality, lesser water access accentuate experiences and perceptions of stresses such as water scarcity.

Overall, farmers in both locations described their area as receiving sufficient rainfall, with a trend towards decrease in rainfall amount and increase in rainfall intensity (more rain falling in a shorter duration). Mostly, expectations of future climate variability (and hence perceptions of possible risks) were not based on actual probabilities but on what people desired the future to look like (Table 2). In doing so, farmers tended to "mentally replace 'rainfall expected' with 'rainfall hoped for" (Coe and Stern 2011:404). Expectations of future climate are also based on past trends, relative to these temporal landmarks.

Box 1 Ecological indicators of water scarcity and erosion of indigenous knowledge

Local communities interact with their local environment closely and develop perceptions of it through several ecological indicators. These perceptions form a rich body of knowledge referred to as indigenous or traditional knowledge systems (Gupta and Singh 2011) and are passed down generations, most often through oral narratives (Pareek and Trivedi 2011). Apart from phenological indicators, some village elders were reputed 'cloud readers' who kept meticulous diaries about the annual movement and shapes of clouds and could predict the health of the monsoon. Also common were consultations with a 'Pandit' or astrologer usually of the Brahmin caste, who predicted rainfall amount and risk of future natural hazards. The Pandit served multiple roles and also gave information about when people would get married, how a crop would do, and whether the coming year held good or bad omens.

The four farmers who spoke of ecological indicators, were above 60 years; respondents below the age of 30 reported being unable to read any indicators. This suggests that traditional knowledge may be eroding in the face of modern education systems. People also noted that ecological indicators were often proving wrong in recent years, perhaps due to higher climate variability. The following quotes illustrate some ecological indicators farmers use:

'When new leaves come out in the resin giving tree (dhavda) it means rains are about to come. When hilpi (small herbaceous plant) flowers, it means it has rained somewhere close by and there is moisture in the air. If the fruit of the red cotton silk tree ripen well and cotton flies about, there will be a good rain.' $\mathrm{HH}$ 35_KP

'Earlier we used to collect mahua (Madhuca longifolia) flowers in June but now, because of less rain, the trees have dried.' HH_14_ NA

'When ants and termites start coming out, we know that rains are about to come.' HH_126_J

In contrast, some farmers spoke of modern sources of information like televisions and radios to predict rainfall and came up with (self-made) yet ingenious indicators:

II don't believe in that Pandit. He tells you what you want to hear. I listen to my radio. When they say rains have reached Bombay, I know it will rain here in the next 15 days.' HH_5_NA 
Fig. 2 Indicators farmers use to perceive the risk of water scarcity in both locations. Bars indicate percentage of respondents and numbers signify number of respondents

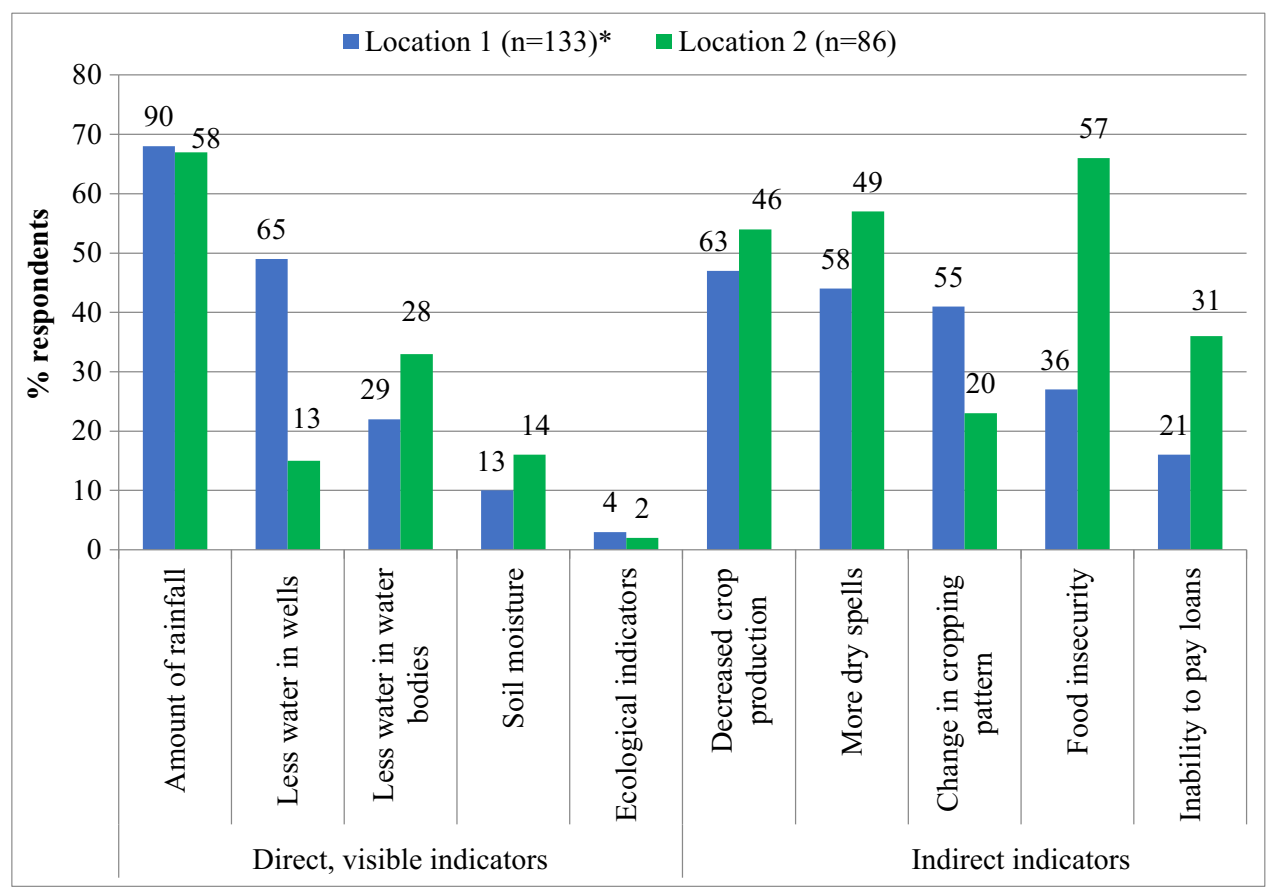

* The total no. of respondents exceeds the sample size of 133 because farmers gave more than one indicator of water scarcity

\section{Differential perceptions of risk of water scarcity}

Perceptions of change in climate variability and water availability differed based on location, landholding size, income levels, and to a lesser extent, gender, education level, age, and well ownership (Table 3).

\section{Location}

In the undulating landscape of Pratapgarh, house and farm location dictated water access (through proximity to streams and ponds), crop productivity (through varying soil fertility), and exposure to environmental hazards (valleys at higher risk of flood than plateaus). Perceptions of water scarcity were significantly higher in location 1 because more hamlets were on plateaus, which were far from water bodies and had hard under-rock that dissuades subsurface percolation (Fig. 3, left). Villages in location 2 ranked water scarcity relatively lower because poor access to farm implements and markets were more pressing issues.

Perceptions of climate variability, captured through changes in rainfall amount and extreme events, show that all hamlets on the plateau reported decreasing rainfall amount. Some respondents in hamlets $\mathrm{HK}$ and $\mathrm{Kh}$ (in the valley) perceiving an increase (Fig. 3, centre). This was because during high intensity rainfall events, flash floods were common in the valley and these high impact, recent events were recalled strongly. Also, most houses and farms in the valley were on steep slopes, and farmers faced detrimental effects of rain like washing away of top soil, crop destruction, reduced fodder availability, and damage to mud huts. In Hamlets $\mathrm{J}$ and $\mathrm{K}$, farmers (22 and $31 \%$ respectively) reported rainfall amount to be same. This could be because farmers here have wells and access to the village pond, mitigating impacts of withinseason dry spells.

Farmers in poorer, more isolated hamlets $(\mathrm{CP}, \mathrm{KP}, \mathrm{HK}$ and $\mathrm{Kh}$ ) reported increased frequency of dry spells and heavy rainfall events more than the relatively well-connected hamlets (Fig. 3, right). Since poorer households are more acutely affected by extreme events, they tended to perceive changes in rainfall variability more strongly. Heightened perceptions in some

Table 3 Factors affecting perceptions of exposure water scarcity and climate variability

\begin{tabular}{lll}
\hline Parameter & $\begin{array}{l}\text { Water scarcity } \\
\text { ranking }\end{array}$ & $\begin{array}{l}\text { Perceptions of } \\
\text { climate variability }\end{array}$ \\
\hline Location & $73.244^{* *}$ & $67.833^{* *}$ \\
Well ownership & 24.452 & 22.812 \\
Landholding size & $36.993^{* *}$ & 19.185 \\
Income & $21.572^{*}$ & 17.052 \\
Level of education & 15.393 & 9.048 \\
Age & 14.208 & 8.330 \\
Gender & .674 & $16.868^{*}$ \\
\hline
\end{tabular}

A chi-square test was run for each pair of variables. Significant associations are flagged

${ }^{1}$ Denoted through change in rainfall amount over past 10 years. $* * p<$ $0.001, * p<0.05$ 


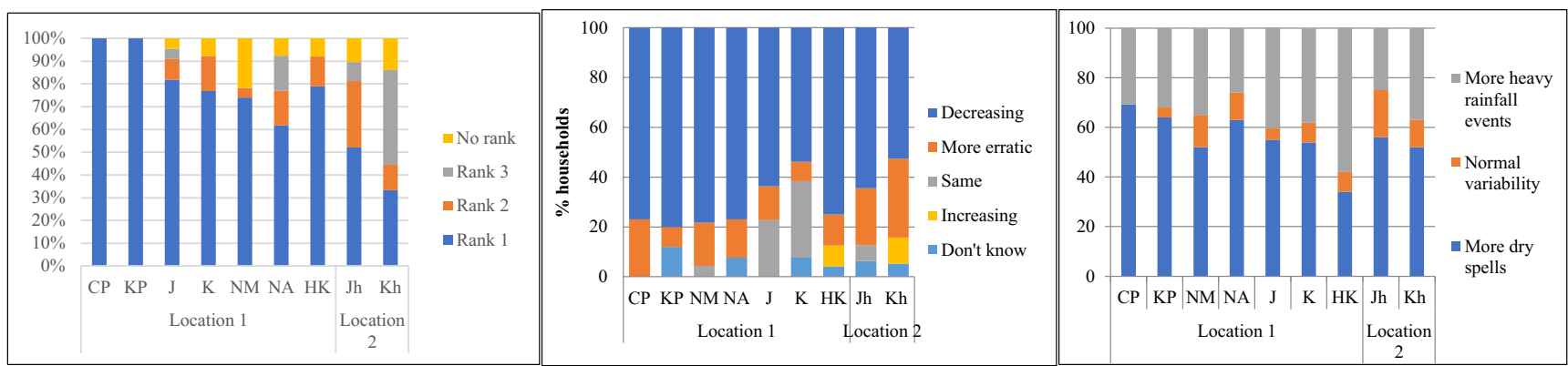

*During the household survey, farmers were asked to name and rank three factors that most limited their agriculture. Each limiting factor identified was given a score of 3 (most limiting), 2 or 1 (least limiting to their agriculture). A score of zero was given to any factor that was not identified.

**Examples of the questions asked about change include: "In the past 10 years, has the amount of rainfall changed?" to elicit information about perceptions of change in the rainfall amount; "From your experience, do extreme events such as drought, floods, heavy rain etc. affect your agriculture?" to initiate perceptions of extreme events and these were followed by additional questions about why and how.

Fig. 3 Hamlet-wise breakup of perceptions of water scarcity (left) ${ }^{*}$, change in rainfall amount (centre) and extreme rain events (right) ${ }^{* * *}$

hamlets were the result of differential information access. For example: in location 1, Hamlets CP and KP have limited road connectivity or NGO presence contributing to less participation in local government meetings; Hamlets $\mathrm{J}$ and $\mathrm{K}$ are close to roads, have better access to newspapers, shopkeepers and NGO staff, contributing to their awareness of government-funded distribution of free maize seed; Hamlets $\mathrm{J}$ and $\mathrm{K}$ have access to popular media and regular contact with extension workers and were more articulate about climate change, as depicted through dominant discourses of global warming (longer droughts, glaciers melting, sea-level rise etc.).

\section{Assets and sharing norms}

Households with wells coped with water scarcity better because the additional water helped tide over dry spells and grow a winter crop. Some households shared wells with other family members (usually father or brothers). Depending on how much water there was in the shared well and how cordial relations were between family members, such households were either water secure or water constrained. This experience of water security (or lack of it) drove perceptions of water being sufficient (or not) (see Supplementary Material for graphs).

As expected, farmers with no access to wells or common water bodies ranked water scarcity high. However, $80 \%$ of farmers owning wells also ranked water scarcity high. Discussions highlighted that most wells were either old, shallow (the average depth being $3 \mathrm{ft}$ ), or heavily silted and could not hold much water. Of farmers with shared wells, 90\% ranked water scarcity as the main constraining factor, which is higher than farmers with no access $(80 \%)$ or reliant solely on common water resources (70\%). This quote sheds some light:

\footnotetext{
'My father and five brothers share the family well which is old with hardly any water. First my elder brother draws water and then the second eldest. Since I am the youngest, I hardly get any. I cannot say anything to
}

them since they are elder with larger families than mine.

Sometimes we fight, but we always resolve things within ourselves.' HH_34_K.

Interestingly, people with access to both shared and own wells used their own wells first because these were perceived as an assured supply of water. The shared wells were ridden with conflict and marked with uncertainty (all users needing water within the short growing season). Thus, though such farmers had access to both own and shared wells, their water availability was closer to those who had only their own wells since the shared ones were not a reliable option. This highlights that familial ties and kinship networks affect well ownership directly with indirect implications on perceptions of water availability.

Access to wells and common water resources like streams and ponds also affected perceptions of changes in rainfall. Respondents with own/shared wells perceived a decrease in rainfall amount because water level in wells was used as an indicator of water scarcity. Those without access to either common water resources or wells replied with 'don't know', indicating that they did not perceive changes in rainfall amount as strongly because they did not have the access to those indicators.

Respondents across income categories ranked water scarcity high and perceived decrease in rainfall (Fig. 4, top), perhaps because income disparity within locations was not wide. Interestingly, only the very poor (BPL and CPL) reported increase in rainfall. In the absence of proper huts, they are most exposed to damage from strong rains and floods, leading to stronger perceptions.

Perceptions of water scarcity were significantly linked to landholding size with larger landholders perceiving erratic rainfall behaviour more than smallholders (Fig. 4, bottom). This may be because large landholders diversified into different crops, some of which were weather sensitive. Farmers growing weather-sensitive crops such as caraway and cumin had heightened perceptions of climatic fluctuations since cumin and caraway need a moisture-free period towards the end of 


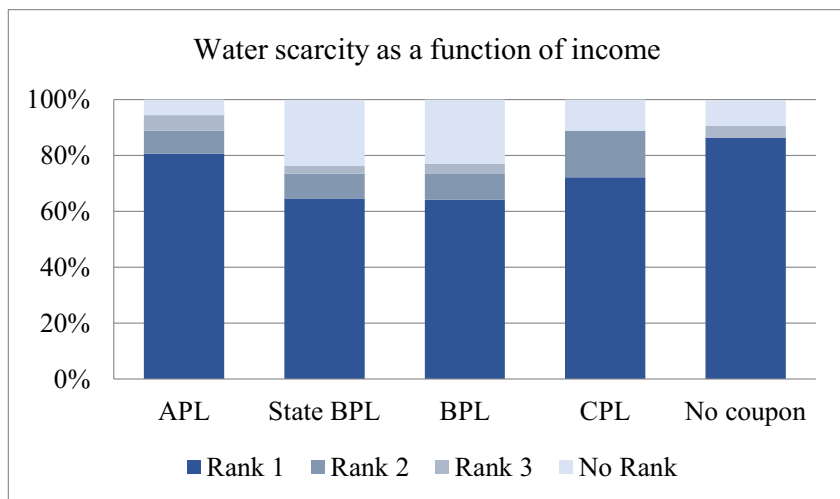

Rainfall perceptions as a function of income
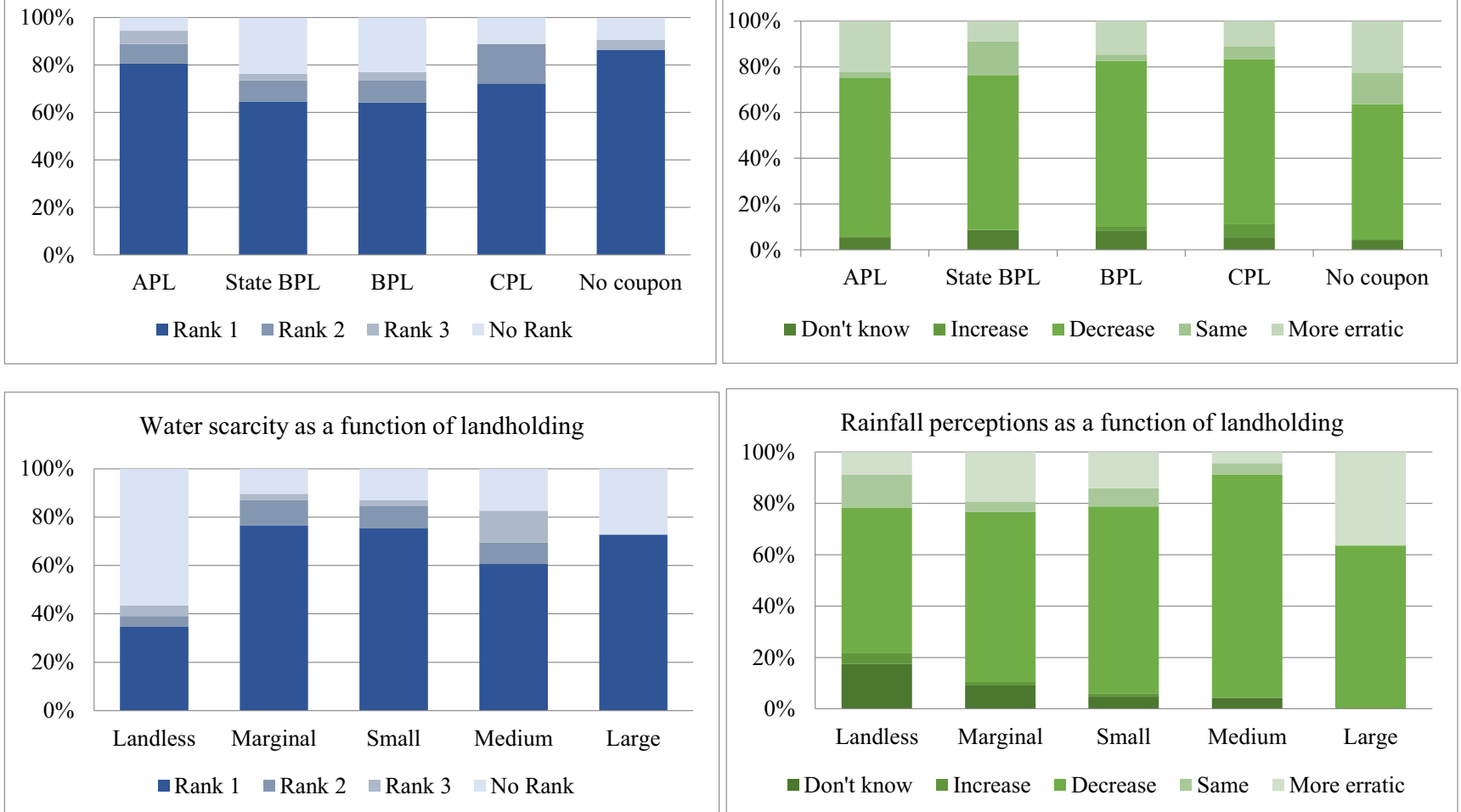

Fig. 4 Household income and perceptions of rainfall variability and water scarcity (top), landholding size and perceptions of rainfall variability and water scarcity (bottom). APL $=$ Above poverty line, State BPL $=$ Below

the growing season. In contrast, farmers growing soybean and maize did not report any change in temperature or incidences of frost; clearly demonstrating that 'a 'bad' year for one farmer may be 'good' for another' (Simelton et al. 2011:8).

\section{Age and farming experience}

Those who had been farming for many years had sharper perceptions of water scarcity than young farmers (see Supplementary Material for graphs) perhaps because young farmers were increasing exposed to other non-climate limiting factors. Older people were not as involved in accessing agriculture inputs and hence did not feel the impact of unavailability of inputs or issues of restricted market access.

During conversations about climate variability, respondents often alluded to 'how it was earlier' versus 'present conditions'. This comparison comes easier to farmers with a body of experience to draw on and use as reference points. Young farmers could not draw on long-term rainfall patterns and relied on present conditions to develop their understanding of the climate. Thus, more experienced farmers defined water scarcity in terms of 'water stays in the stream for 6 months instead of 8 months as it used to 10 years ago' (HH_13_NA). However, as discussed earlier, age did not have

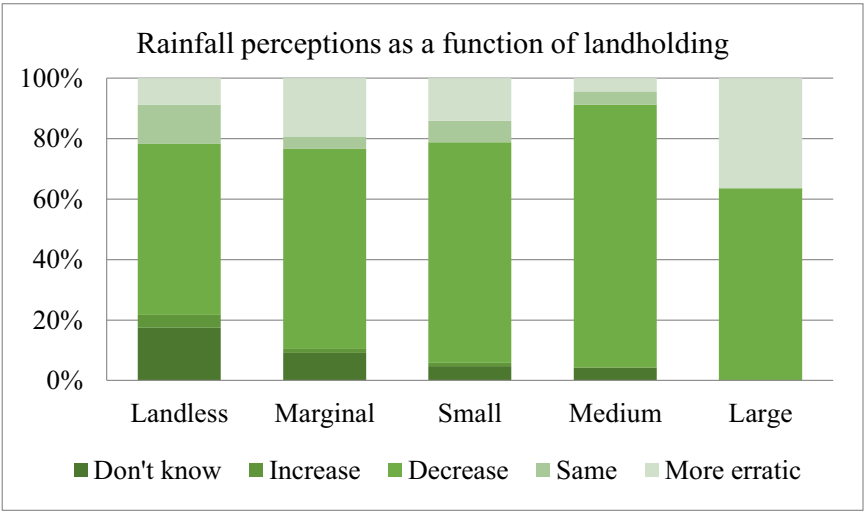

poverty line identified by state government, $\mathrm{BPL}=$ Below poverty line identified by central government, $\mathrm{CPL}=$ Antodaya or Poorest of the poor

as much of an influence on memory: while older farmers narrated their experiences of extreme events like droughts, younger people narrated those narrations as if their own, reconfirming the observation that memory can be shared or collective with experiences and stories passed down through generations. Thus, people spoke of 'a time when it rained so much that the grasses were so tall that no one could cut them' (HH 65 NM). While respondents in their 30s had not seen such a time in their own lifetime, they relied on stories they had heard, and thus, these had become part of their own memories and shaped their perceptions of the past (thus moulding their reference point, which they compared to the present).

\section{Gender and caste}

Both male and female-headed households ranked water scarcity as the main limiting factor to agriculture. However, perceptions of change in rainfall amount differed significantly by gender. Both men and women perceived rainfall to be decreasing but significantly more women (14\%) replied 'do not know'. Since access to weather information was mainly from radio, mobile phones, through shopkeepers, and informal (typically all-male) meetings between neighbours in the evenings, women did not have access to information in the same 
way as men do. 'My husband has gone for Gram Panchayat meeting to get maize seed. The men talk about agricultural issues there. He also went to Kishangarh (key town) two years ago...' 'Of course I didn't go!' HH_67_K Also, the spheres men and women operate in (farming and domestic duties respectively), are clearly demarcated. You should ask my husband about the well. I go to collect water for the house from the hand pump so I can tell you about that.' HH_72_Kh.

Through a narrowing of the channels and spaces that women occupy either publicly (village meetings) or privately (on farms, within homes) often resulted in women being less articulate about climate than men. Men were more tuned to changes in temperature, frost, and soil moisture, while women only reported changes in rainfall amount. This was perhaps because rainfall amount directly affects groundwater recharge and hence drinking water resources like wells, hand pumps, and streams. Men noticed other climatic factors because they were engaged in the day-to-day activities of agriculture.

In Rajput households, caste and gender intersected so that the divide between roles of men and women was sharper: women confined to the domestic sphere and men solely responsible for agriculture-related work. The demarcation was so unyielding that some women reported never having left their house, while others report rarely seeing their farmland. Such female respondents tended to refrain from holding any perceptions of water scarcity or climate variability and if they did, they tended to agree with their male family members.

\section{Discussion}

\section{Drivers of perceptions of water scarcity}

Farmer perceptions of water scarcity were an outcome of an intricate interplay of their definitions of water scarcity, personal and borrowed memories, experiences of past events, and expectations of future risk (Fig. 5). Perceptions were mediated by normative beliefs, caste-specific gender roles, asset holdings, and age.

Respondent memories of water scarcity and drought were subjective with a bias for the present. Respondents gave more weightage to recent events because the consequences were perceived more strongly than those in the distant past. Although people recalled rare and acute events like intense droughts with more clarity, they were considered as 'one-time events' to which people attached a low probability of recurrence (Marx et al. 2007). Memory was also signposted by important personal or political events thus highlighting that cross-scale processes and events may affect memory and hence risk perception.

Farmers underreported drought which contrasted with historical data. This was because regular experiences with water scarcity and moderate drought had habituated farmers and built a high threshold to it (Slegers 2008b). This 'prison of experience' (Kates 1962 p. 132) emphasises that in order to perceive a hazard as a threat, people need to experience it in a

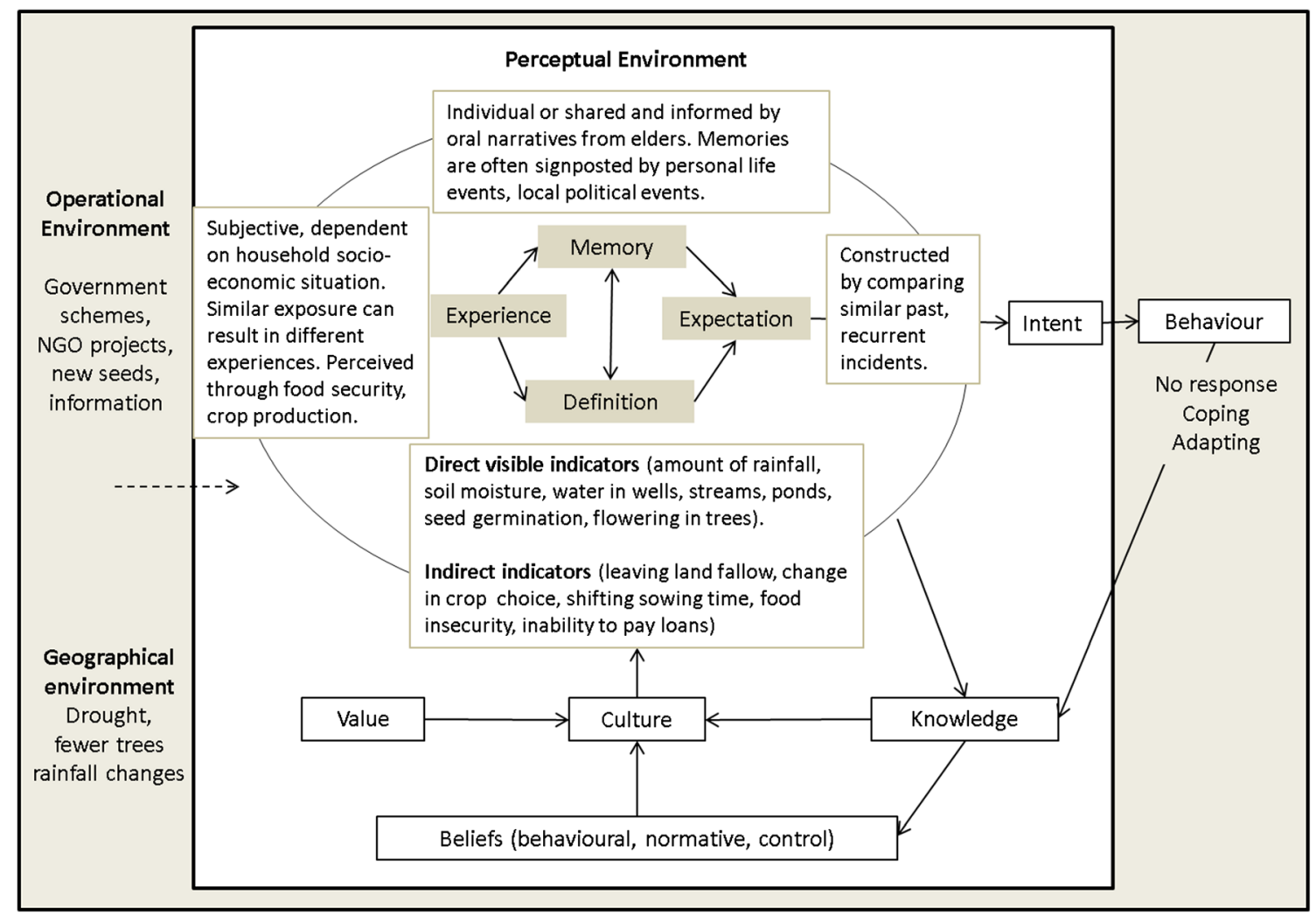

Fig. 5 Factors shaping farmer perceptions of water scarcity and climate variability as shown through the conceptual analysis of the data 
certain magnitude with a certain frequency. Severe drought once every 25 years (as in Pratapgarh) was perceived too improbable and moderate droughts and dry spells too common to be reported.

Expectations of future climate variability were based on existing definitions of 'normal' climate, cultural norms like traditional calendars, and to a lesser extent, information from external sources. Most often, these expectations of perceptions of future climate-related risks were not based on actual probabilities but on what people desired the future to look like (Simelton et al. 2011) and thus had implications for anticipatory adaptation.

Disentangling perceptions of climate from its impacts were difficult, and farmers often misattributed water scarcity to reduced rainfall; a finding not supported by meteorological trends (Singh 2014). These perceptions were obfuscated by dynamics in the operational and geographical environments such as input availability, fluctuations in market rates, and broader discourses of environmental change through newspapers, extension agents and NGO workers.

\section{Explaining differential perceptions of water scarcity}

Overall, farmers perceived water scarcity as the main factor limiting agriculture. However, perceptions differed along geographical factors (location, soil type), agricultural assets (well ownership, crops grown), and individual characteristics (age, experience of farming, gender, and caste) (Table 3).

Broadly, respondents living on the plateau (fewer wells, poor soil quality, and more soil erosion) perceived water scarcity as the only limiting factor for agriculture. Interestingly, all hamlets reported those in the valley to be water-rich because it has access to village streams. However, respondents in the valley perceived themselves to be water constrained, noting that locally, shallow wells were predominant and these only recharged in a good rainy season. This dependence on a good monsoon made farmers in the valley vulnerable to monsoonal variability. Thus, geographical location and well ownership affected perceptions of water scarcity.

Crucially, access to common water resources and well ownership did not always translate into higher water availability. This was because wells were often shallow, silted, or old, and constrained by inadequate irrigation infrastructure, erratic electricity supply, and high costs of diesel. Thus, beyond rainfall amount and presence of water bodies, broader factors shape the perception and experience of water scarcity. Farmers growing weather-sensitive crops such as caraway had heightened perceptions regarding climatic fluctuations because of the potentially higher losses involved.

Demographic characteristics directly affected ability to access and understand information from different sources. In particular, older farmers drew on experience to make comparisons of past and present climate. Women were less articulate about changes in climatic variability because of differential information access and strongly defined roles where men were in-charge of agricultural activities and women responsible for domestic chores.

\section{The role of misattribution}

One complication in studying perceptions of climate variability is the difficulty in disengaging perceptions of events (actual rainfall) from their impacts such as decreased crop production or food insecurity (Marx et al. 2007; Rao et al. 2011). The range of direct and indirect indicators farmers use to perceive changes in their environment, illustrate that climatic factors are only one of the many factors shaping perceptions.

First, normative beliefs held by family members, neighbours, elders, and shopkeepers (who are often educated and have relatively better access to information) tend to shape perceptions held by farmers. Second, when indirect indicators such as change in crop production or household food security are used to gauge risk, chances of misattribution are high. Though farmers identify water availability as a driver of change in crop productivity, non-climatic dynamics such as changes in soil fertility, fertiliser and seed availability, market accessibility, harvesting losses, or personal reasons like illness in the family may be significant drivers. The following quote illustrates the issue of possible misattribution:

'Our planting schedule has changed: earlier wheat would ripen with soil moisture alone. Now we water up to 4-5 times to get a good crop. And getting so much water is difficult. We don't even have an engine.' Household 49, Hamlet Chhota Pathaar.

The respondent is comparing a time when people grew one crop of rainfed wheat, for which there was sufficient soil moisture. Presently, farmers take two crops a year, driving up water requirements. However, this is not factored into perceptions of decreased water availability. Thus, farmers may attribute water scarcity to declining rainfall when it may be because of increasing water demand due to increased cultivation (Osbahr et al. 2011; Rao et al. 2011).

Third, farmers often base perceptions of water scarcity on changes in crops grown. While this may be driven by changes in water availability, KIIs indicated otherwise. Institutional, economic, and infrastructural changes, such as the promotion of Pratapgarh to a district (leading to better road connectivity), increased presence of private companies directly sourcing raw materials from farmers, improved availability of different seeds, and subsidised loans towards building wells appear to be driving crop choices. Thus, although farmers may perceive that changes in water availability are driving crops choice, the role of wider regional socio-political dynamics (the operational environment) that may be ushering in these changes cannot be overlooked. 


\section{Implications for adaptation policy and practice}

Adaptation is inherently a behavioural change preceded by a process of risk perception and consequent decision-making (Grothmann and Patt 2005; Marx et al. 2007; Singh et al. 2016). Thus, examining what drives risk perception furthers our understanding of the cognitive and behavioural aspects of adaptation. We find that the interrelatedness and complexity of how farmers defined water scarcity and the direct and indirect indicators they used to 'know' it, closely affected their decisions on crop choice and livelihood investments. Understanding these ways of knowing, which may differ from scientific definitions of drought and water scarcity, is thus crucial for incentivising and institutionalising adaptive behaviour. This adds to a growing literature that demonstrates how dissonances between farmers' and scientists' ways of knowing environmental change (Burnham et al. 2016; Popke 2016) feed into adaptation investment and policy development (Birkenholtz 2014; Goldman et al. 2016; Stock et al. 2017).

We found that water scarcity is differentially perceived and experienced by individuals, households and communities. Separating these perceptions of water scarcity, climate variability and incidence of events (for example heavy rainfall) from the impacts they have on agriculture (for example decreased crop production) is complex (Marx et al. 2007; Rao et al. 2011; Simelton et al. 2011) and artificial. Cross-scale, nonclimatic factors like differential water availability and access, crop changes, reduced soil fertility and unavailability of good quality, and timely seeds and fertiliser affected water availability. We argue that while the climate is an important factor shaping farmer perceptions of water scarcity, the climate change and erratic weather narrative potentially obscures other non-climatic drivers of farmer vulnerability. Such a focus on climate change alone downplays the multiple risks (constructed through perceptions of past and present socioenvironmental factors) that shape household response pathways. From a policy perspective, the findings emphasise the need for recognising plural knowledge systems where local perceptions of risk are factored into adaptation plans as meteorological trends and climate projections are. They also inform adaptation implementation by demonstrating that a focus on climatic risks alone downplays the role of inter- and intrahousehold factors in mediating social vulnerability-factors such as location, asset bases, age and gender critically shape risks and responses. Such evidence calls for adaptation interventions to be more holistic and factor in multiple risks as perceived by vulnerable individuals.

Projections of higher rainfall variability and evapotranspiration rates in Rajasthan (Singh et al. 2010) highlight the need for investing in strategies that can support farmers to store rain when and where it falls. While the recent Pradhan Mantri Krishi Sinchai Yojana (Prime Minister Agriculture Irrigation Scheme) is a promising step towards improved water management, top-down climate scenarios and water use models need to be corroborated with local perceptions of risk for effective adaptation. Focussing on improving water use efficiency, storing rainwater, creating competitive prices for millets and oilseeds, and improving climate information services, especially to women and older people are some possible strategies.

Finally, changes in the operational environment through wider institutional, socio-economic, and infrastructural dynamics are shaping rural livelihoods and must be factored into adaptation planning.

\section{Conclusion}

Against the hypothesis that only if risk is perceived can it be managed or responded to, drivers of differential farmer perceptions were explored to understand factors underlying differential response behaviour. Perceptions of water scarcity and climate variability in Pratapgarh were shaped by individual and collective memory, past experiences and future expectations, and their definitions of stressors. Geographical factors such as location, assets such as income, access to wells and common water bodies, and demographic factors such as age, gender and caste, interact to shape the experience and perception of water scarcity. Climate variability emerged as one among several factors driving perceptions of water scarcity, highlighting the need for addressing non-climatic reasons for water scarcity. We found that there are multiple ways of 'knowing' climate and the focus on 'climate change' has obscured the other livelihood factors that people perceive as drivers of vulnerability. One of the key contributions of our approach is to help reframe this understanding of risk perception and consider how it may affect behaviour and therefore pathways of response.

Overall, we found Slegers' framework of risk perception (Slegers 2008b), which highlights the role of memory, experience, definition, and expectation as key factors that construct meaning and perceptions (Fig. 1), useful to make sense of local perceptions of water scarcity and climate variability in Pratapgarh. By highlighting the role of local beliefs and practices, and normative values, the framework allows us to emphasise how socio-cognitive and normative factors shape risk perception and consequently, adaptive behaviour. While linkages with the operational and geographical environment (e.g. instituional and ecological factors respectively) help place risk perceptions in a broader context, future research can operationalise these cross-scalar and beyond-local factors further. This will extend this paper's contribution on demonstrating how local risk perception and adaptive behaviour is constructed by local and beyond-local factors.

Differences in farmer perceptions provide insights into why some farmers choose to adapt while some do not and how subjective perceptions influence decision-making to respond to external risks. Thus, initiatives to encourage adaptive 
behaviour must account not only for farmer perceptions of risk, but also acknowledge that these perceptions differ based on social, economic and personal factors, and thus lead to differential behavioural outcomes (to adapt or not to adapt). For example, women-headed households or older farmers may need targeted adaptation support because their perceptions of risk and hence motivations to adapt are significantly different from young male farmers (with better information access) or experienced male-headed households (who may have higher experiential understanding of past climate events and associated impacts). When planning for risk management in general, and climate change adaptation specifically, it is important to understand how farmer perceptions of environmental changes shape social vulnerability, response behaviour, and trajectories of change in dryland areas.

Acknowledgements This work formed part of the first author's $\mathrm{PhD}$ research (University of Reading, 2014), which was funded by The Felix Trust, UK. Opinions expressed and conclusions are those of the authors. We thank Foundation for Ecological Security (FES) for hosting the fieldwork in Pratapgarh. We also acknowledge valuable comments from two anonymous reviewers on a previous version of this paper.

Open Access This article is distributed under the terms of the Creative Commons Attribution 4.0 International License (http:// creativecommons.org/licenses/by/4.0/), which permits unrestricted use, distribution, and reproduction in any medium, provided you give appropriate credit to the original author(s) and the source, provide a link to the Creative Commons license, and indicate if changes were made.

\section{References}

Adger WN, Hughes TP, Folke C, Carpenter SR, Rockström J (2005) Social-ecological resilience to coastal disasters. Science (80) 309: 1036-1039. https://doi.org/10.1126/science.1112122

Adger WN, Barnett J, Brown K, Marshall N, O'Brien K (2013) Cultural dimensions of climate change impacts and adaptation. Nat Clim Chang 3:112-117. https://doi.org/10.1038/nclimate1666

Ajai Arya AS, Dhinwa PS, Pathan SK, Raj KG (2009) Desertification/ land degradation status mapping of India. Curr Sci 97:1478-1483

Arunrat N, Wang C, Pumijumnong N, Sereenonchai S, Cai W (2017) Farmers's intention and decision to adapt to climate change: a case study in the Yom and Nan basins, Phichit province of Thailand. J Clean Prod 143:672-685. https://doi.org/10.1016/j.jclepro.2016.12. 058

Banerjee RR (2014) Farmers' perception of climate change, impact and adaptation strategies: a case study of four villages in the semi-arid regions of India. Nat Hazards 75:2829-2845. https://doi.org/10. 1007/s11069-014-1466-z

Becken S, Lama AK, Espiner S (2013) The cultural context of climate change impacts: perceptions among community members in the Annapurna conservation area, Nepal. Environ Dev 8:22-37. https://doi.org/10.1016/j.envdev.2013.05.007

Birkenholtz T (2014) Knowing climate change: local social institutions and adaptation in Indian groundwater irrigation. Prof Geogr 66:354362. https://doi.org/10.1080/00330124.2013.821721

Bowditch JL, Buono AF, Stewart MM (2001) A primer on organizational behavior. Wiley, New York
Burnham M, Ma Z, Zhang B (2016) Making sense of climate change: hybrid epistemologies, socio-natural assemblages and smallholder knowledge. Area 48:18-26. https://doi.org/10.1111/area.12150

Coe R, Stern RD (2011) Assessing and addressing climate-induced risk in Sub-Saharan Rainfed agriculture: lessons learned. Exp Agric 47: 395-410. https://doi.org/10.1017/S001447971100010X

Curry GN, Koczberski G, Lummani J, Nailina R, Peter E, McNally G, Kuaimba O (2015) A bridge too far? The influence of socio-cultural values on the adaptation responses of smallholders to a devastating pest outbreak in cocoa. Glob Environ Chang 35:1-11. https://doi. org/10.1016/j.gloenvcha.2015.07.012

De A (2005) Mediation in adaptive management of water resources: resistance to Borewells at the grassroots, and implications for groundwater policy action, working paper 16. Foundation for Ecological Security, Anand

Dhanya P, Ramachandran A (2016) Farmers' perceptions of climate change and the proposed agriculture adaptation strategies in a semi arid region of south India. J Integr Environ Sci 13:1-18. https://doi. org/10.1080/1943815X.2015.1062031

Eakin H, York A, Aggarwal R, Waters S, Welch J, Rubiños C, Smith-Heisters S, Bausch C, Anderies JM (2016) Cognitive and institutional influences on farmers' adaptive capacity: insights into barriers and opportunities for transformative change in central Arizona. Reg Environ Chang 16:801814. https://doi.org/10.1007/s10113-015-0789-y

Elrick-Barr CE, Thomsen DC, Preston BL, Smith TF (2016) Perceptions matter: household adaptive capacity and capability in two Australian coastal communities. Reg Environ Chang 17:1-11. https://doi.org/ 10.1007/s10113-016-1016-1

Eriksen SH, Nightingale AJ, Eakin H (2015) Reframing adaptation: the political nature of climate change adaptation. Glob Environ Chang 35:523-533. https://doi.org/10.1016/j.gloenvcha.2015.09.014

Feng X, Liu M, Huo X, Ma W (2017) What motivates farmers' adaptation to climate change? The case of apple farmers of Shaanxi in China. Sustainability 9:519. https://doi.org/10.3390/su9040519

Feola G, Lerner AM, Jain M, Montefrio MJF, Nicholas K (2015) Researching farmer behaviour in climate change adaptation and sustainable agriculture: lessons learned from five case studies. J Rural Stud 39:74-84. https://doi.org/10.1016/j.jrurstud.2015.03.009

Ferrier N, Haque CE (2003) Hazards risk assessment methodology for emergency managers: a standardized framework for application. Nat Hazards 28:271-290. https://doi.org/10.1023/A:1022986226340

Fishbein M, Ajzen I (2011) Predicting and changing behavior: the reasoned action approach. Taylor \& Francis

Folke C (2006) Resilience: the emergence of a perspective for socialecological systems analyses. Glob Environ Chang 16:253-267. https://doi.org/10.1016/j.gloenvcha.2006.04.002

Foundation for Ecological Security (2006) NABARD ITC Indo-German Watershed Development Programme (Kherot 3 Watershed). Project Proposal submitted to NABARD, Udaipur. Foundation for Ecological Security

Gbetibouo GA (2009) Understanding farmers' perceptions and adaptations to climate change and variability: the case of the Limpopo Basin, South Africa. IFPRI Discuss. Pap. 00849 52. https://doi. org/10.1068/a312017

Goel A, Singh RB, Goyal A (2006) Climatic variability and drought in Rajasthan. Adv Geosci 4:57-67. https://doi.org/10.1142/ 97898127072080007

Goldman MJ, Daly M, Lovell EJ (2016) Exploring multiple ontologies of drought in agro-pastoral regions of northern Tanzania: a topological approach. Area 48:27-33. https://doi.org/10.1111/area.12212

Gosling SN, Arnell NW (2016) A global assessment of the impact of climate change on water scarcity. Clim Chang 134(3):371-385. https://doi.org/10.1007/s10584-013-0853-x

Government of Rajasthan (2005) Rajasthan relief manual. Jaipur, India

Government of Rajasthan (2014) Rajasthan state action plan on climate change. Jaipur, India 
Grothmann T, Patt A (2005) Adaptive capacity and human cognition: the process of individual adaptation to climate change. Glob Environ Chang 15:199-213. https://doi.org/10.1016/j.gloenvcha.2005.01.002

Grothmann T, Grecksch K, Winges M, Siebenhüner B (2013) Assessing institutional capacities to adapt to climate change: integrating psychological dimensions in the adaptive capacity wheel. Nat Hazards Earth Syst Sci 13:3369-3384. https://doi.org/10.5194/nhess-13-3369-2013

Gupta AK, Singh A (2011) Traditional intellect in disaster risk mitigation: Indian outlook - Rajasthan and Bundelkhand Icons 10:156-166

Hulme M, Dessai S, Lorenzoni I, Nelson DR (2009) Unstable climates: exploring the statistical and social constructions of "normal" climate. Geoforum 40:197-206. https://doi.org/10.1016/j.geoforum.2008.09.010

Kates RW (1962) Hazard and choice perception in flood plain management. University of Chicago, Chicago

Maddison D (2007) The perception of and adaptation to climate change in Africa. World Bank Policy Res Work Pap 46

Mall RK, Gupta A, Singh RS, Rathore LS (2006) Water resources and climate change: an Indian perspective. Curr Sci 90:1610-1626

Martínez-García CG, Dorward P, Rehman T (2013) Factors influencing adoption of improved grassland management by small-scale dairy farmers in central Mexico and the implications for future research on smallholder adoption in developing countries. Livest Sci 152:228 238. https://doi.org/10.1016/j.livsci.2012.10.007

Marx SM, Weber EU, Orlove BS, Leiserowitz A, Krantz DH, Roncoli C, Phillips J (2007) Communication and mental processes: experiential and analytic processing of uncertain climate information. Glob Environ Chang 17:47-58. https://doi.org/10.1016/j.gloenvcha.2006.10.004

McDonald RI, Chai HY, Newell BR (2015) Personal experience and the "psychological distance" of climate change: an integrative review. J Environ Psychol 44:109-118. https://doi.org/10.1016/j.jenvp.2015. 10.003

Mekonnen MM, Hoekstra AY (2016) Four billion people facing severe water scarcity. Sci Adv 2(2):1-6. https://doi.org/10.1126/sciadv.1500323

Mertz O, Mbow C, Reenberg A, Diouf A (2009) Farmers' perceptions of climate change and agricultural adaptation strategies in rural sahel. Environ Manag 43:804-816. https://doi.org/10.1007/s00267-0089197-0

Meze-Hausken E (2004) Contrasting climate variability and meteorological drought with perceived drought and climate change in northern Ethiopia. Clim Res 27:19-31. https://doi.org/10.3354/cr027019

Mubaya CP, Njuki J, Mutsvangwa EP, Mugabe FT, Nanja D (2012) Climate variability and change or multiple stressors? Farmer perceptions regarding threats to livelihoods in Zimbabwe and Zambia. J Environ Manag 102:9-17. https://doi.org/10.1016/j.jenvman.2012. 02.005

Murray-Prior R (1998) Modelling farmer behaviour: a personal construct theory interpretation of hierarchical decision models. Agric Syst 57: 541-556. https://doi.org/10.1016/S0308-521X(98)00008-0

Nguyen TPL, Seddaiu G, Virdis SGP, Tidore C, Pasqui M, Roggero PP (2016) Perceiving to learn or learning to perceive? Understanding farmers' perceptions and adaptation to climate uncertainties. Agric Syst 143:205-216. https://doi.org/10.1016/j.agsy.2016.01.001

Olick JK, Robbins J (1998) Social memory studies: from "collective memory" to the historical sociology of mnemonic practices. Annu Rev Sociol 24:105-140. https://doi.org/10.1146/annurev.soc.24.1.105

Osbahr H, Dorward P, Stern R, Cooper S (2011) Supporting agricultural innovation in Uganda to respond to climate risk: linking climate change and variability with farmer perceptions. Exp Agric 47: 293-316. https://doi.org/10.1017/S0014479710000785

Pareek A, Trivedi PC (2011) Cultural values and indigenous knowledge of climate change and disaster prediction in Rajasthan, India. Indian J Tradit Knowl 10:183-189

Patt AG, Schröter D (2008) Perceptions of climate risk in Mozambique: implications for the success of adaptation strategies. Glob Environ Chang 18:458-467. https://doi.org/10.1016/j.gloenvcha.2008.04.002
Popke J (2016) Researching the hybrid geographies of climate change: reflections from the field. Area 48:2-6. https://doi.org/10.1111/area. 12220

Pratapgarh NIC (2012) Pratapgarh District Information [WWW Document]. URL http://pratapgarh.rajasthan.gov.in/content/raj/ pratapgarh/en/home.html (accessed 9.10.12)

QSR (2012) NVIVO qualitative data analysis software. QSR Int. Ltd. Version 9

Rajesh (2000) Drought, debt and poverty. Econ Polit Wkly 35:21012104

Rao KPC, Ndegwa WG, Kizito K, Oyoo A (2011) Climate variability and change: farmer perceptions and understanding of intra-seasonal variability in rainfall and associated risk in semi-arid Kenya. Exp Agric 47:267-291. https://doi.org/10.1017/S0014479710000918

Rathore MS (2005) State level analysis of drought policies and impacts in Rajasthan. India. Working Paper 93, Drought Series Paper 6, International Water Management Institute, Sri Lanka, p 29

Scannell L, Gifford R (2017) The experienced psychological benefits of place attachment. J Environ Psychol 51:256-269. https://doi.org/10. 1016/j.jenvp.2017.04.001

Simelton E, Quinn CH, Antwi-Agegi P, Batisani N, Dougill AJ, Fraser EDG, Mkwambisi D, Rosell S, Sallu S, Stringer LC (2011) African farmers' perceptions of erratic rainfall. Centre for Climate Change Economics and Policy (CCCEP) Paper No. 73, University of Leeds 36p https://www.cccep.ac.uk/wp-content/uploads/2015/10/WP73 african-famers-perceptions-rainfall.pdf

Simelton E, Quinn CH, Batisani N, Dougill AJ, Dyer JC, Fraser EDG, Mkwambisi D, Sallu S, Stringer LC (2013) Is rainfall really changing? Farmers' perceptions, meteorological data, and policy implications. Clim Dev 5:123-138. https://doi.org/10.1080/17565529.2012.751893

Singh VS, Pandey DN, Gupta AK, Ravindranath NH (2010) Climate change impacts, mitigation and adaptation: science for generating policy options in Rajasthan, India 163

Singh C, Dorward P, Osbahr H (2016) Developing a holistic approach to the analysis of farmer decision-making: implications for adaptation policy and practice in developing countries. Land Use Policy 59: 329-343. https://doi.org/10.1016/j.landusepol.2016.06.041

Slegers MFW (2008a) Exploring farmers' perceptions of drought in Tanzania and Ethiopia. J Arid Environ 72:2106-2123. https://doi. org/10.1016/j.jaridenv.2008.06.011

Slegers MFW (2008b) "If only it would rain": farmers' perceptions of rainfall and drought in semi-arid central Tanzania. J Arid Environ 72:2106-2123. https://doi.org/10.1016/j.jaridenv.2008.06.011

Stock R, Birkenholtz T, Garg A (2017) Let the people speak: improving regional adaptation policy by combining adaptive capacity assessments with vulnerability perceptions of farmers in Gujarat, India. Clim Dev:1-15. https://doi.org/10.1080/17565529.2017.1410089

Sutcliffe C, Dougill AJ, Quinn CH (2016) Evidence and perceptions of rainfall change in Malawi: do maize cultivar choices enhance climate change adaptation in sub-Saharan Africa? Reg Environ Chang 16:1215-1224. https://doi.org/10.1007/s10113-015-0842-x

Taylor JG, Stewart TR, Downton M (1988) Perceptions of drought. Environ Behav 20:150-175

Vedwan N (2006) Culture, climate and the environment: local knowledge and perception of climate change among apple growers in northwestern India. J Ecol Anthropol 10:4-18. https://doi.org/10.5038/ 2162-4593.10.1.1

Vedwan N, Rhoades RE (2001) Climate change in the western Himalayas of India: a study of local perception and response. Clim Res 19:109-117

White GF (1966) Formation a role of public attitudes. In: Jarret H (ed) Environmental quality in a growing economy. Johns Hopkins University Press, Baltimore

Wilson GA (2015) Community resilience and social memory. Environ Values 24:227-257. https://doi.org/10.3197/096327114X13947900182157 